\title{
Recirculación en Bombas Centrífugas
}

\section{Recirculation in Centrifugal Pumps}

DOI: $10.46932 / \mathrm{sfjdv3n1-064}$

Received in: Jan 30st, 2021

Accepted in: Feb 1th, 2022

\section{M en C. Francisco Valenzuela Esquivel \\ Instituto Politécnico Nacional}

Escuela Superior de Ingeniería Mecánica y Eléctrica

Sección de Estudios Posgrado e Investigación

Laboratorio de Ingeniería Térmica e Hidráulica Aplicada (Edificio 5, 3er Piso, Tel. 5557296000 ext. 54754)

E-mail: jarsmep@hotmail.com

\section{Dr. Miguel Toledo Velázquez \\ Instituto Politécnico Nacional}

Escuela Superior de Ingeniería Mecánica y Eléctrica

Sección de Estudios Posgrado e Investigación

Laboratorio de Ingeniería Térmica e Hidráulica Aplicada (Edificio 5, 3er Piso, Tel. 5557296000 ext. 54754)

E-mail:mtv49@yahoo.com

\section{RESUMEN}

Los métodos y criterios de diseño de los equipos de bombeo se aplican únicamente en el punto de máxima eficiencia. El diseño de un equipo de bombeo trata de lograr la máxima eficiencia a una capacidad, carga y velocidad, conducido por estudios hidráulicos para determinar los requerimientos que aseguren un consumo mínimo de energía. De igual forma los principales parámetros de diseño para el cálculo de las dimensiones y forma de la bomba se establecen con la misma metodología.

Sin embargo, se ha tocado poco el tema de la operación fuera del punto de máxima eficiencia en los requerimientos de los parámetros de diseño, no habiendo una referencia específica dentro del cálculo del impulsor necesaria para satisfacer posibles requerimientos o problemas que se presenten al operar el equipo de bombeo fuera de éste punto.

Palabras Clave: Cavitación, Eficiencia, Erosión, Impulsor, Recirculación.

\begin{abstract}
One of the persistent and puzzling problems encountered in centrifugal pump operation in recent years has been recirculation. Recirculation in a centrifugal pump is defined as reverse flow at the suction or discharge of the impeller. Many investigations have observed and reported the existence of back flow, both in the impeller eye and in the impeller discharge under certain operating conditions. All impellers have a point on the curve where recirculation occurs at the impeller suction and another where recirculation occurs at the impeller discharge for the same specific speed and depending on the size and speed of the pump, the effect may occur very damaging, not only in the operation of the pump, but also in the life of the impeller and casing.
\end{abstract}

Keywords: Cavitation, Efficiency, Erosion, Impeler, Recirculation. 


\section{INTRODUCCIÓN}

Cualquier gasto fuera del punto de diseño o punto de máxima eficiencia, independientemente a que su patrón de flujo fuera uniforme al inicio, tendrá una variación en las líneas de corriente, que dependerán del tipo y configuración de equipo de bombeo.

En las proximidades del ojo del impulsor, a una capacidad reducida, la energía cinética del fluido, es menor que la que se presenta en el gasto de diseño. Así mismo, la velocidad promedio disminuye de manera proporcional a la reducción del flujo, pero la velocidad local no disminuye de la misma forma a través de los pasajes hidráulicos. Las partículas del líquido son arrastradas con mayor facilidad hacia las áreas de menor presión y con tendencia a seguir la trayectoria de menor resistencia.

Figura 1. Distribución de velocidades a gasto de bombeo reducido [4]

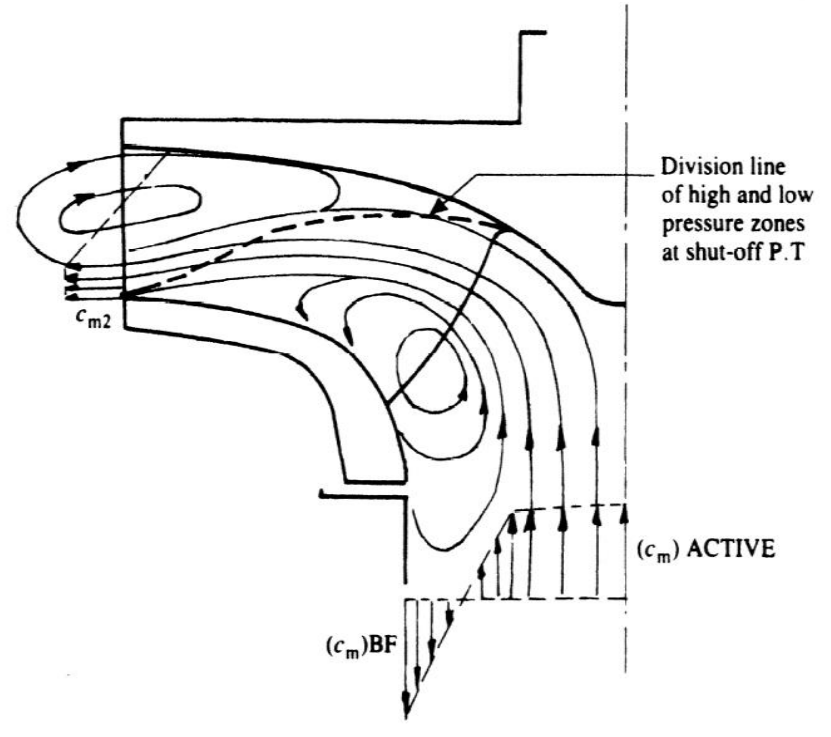

El alejarse del punto de diseño, tiene como consecuencia el inicio del choque del fluido contra las paredes de los álabes. Como la resistencia del flujo se incrementa en relación a cuadrado de la velocidad $\left(\mathrm{W}_{1}\right)^{2}$, las mayores pérdidas se desarrollan en la periferia del impulsor, mayor a la que se presenta en la sección interior o raíz del álabe. De esta forma la reducción del flujo perimetral intensificará la tendencia del impulsor a arrastrar más líquido a la parte interna o central que en la de la periferia, ver figuras 1 y 2.

Como resultado del decremento en la velocidad promedio, se forma un remolino o vórtice en la descarga que causa un incremento en la carga generada, pero la eficiencia total baja por el incremento en las pérdidas hidráulicas del equipo. La obturación del flujo acentúa la tendencia y la redistribución de la velocidad aparece hasta que la dirección del flujo en la succión coincida con la cara de baja presión del álabe. Desde este punto de vista, con la reducción de la capacidad o flujo de la bomba, las líneas de flujo exhiben una tendencia a adherirse a la superficie del lado de baja presión del álabe, desarrollando una componente de flujo en la dirección de la rotación en "un esfuerzo" por llenar las zonas de baja presión 
por la incidencia al crecimiento del flujo relativo. Este proceso contribuye a un continuo crecimiento en la carga generada, atenuada solamente por la sumatoria de las pérdidas generadas en los choques del fluido. La capacidad en la cual el flujo comienza a perder su distribución uniforme y desarrolla una componente de vórtice en la sección periférica y comúnmente se llama capacidad crítica $\mathrm{Q}_{\text {cr. }}$ El cambio

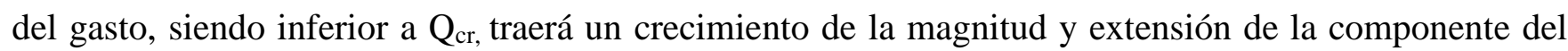
vórtice sobre la superficie del álabe, dejando el resto del pasaje casi totalmente no afectado. Los perfiles de un álabe con pérdida de sustentación comienzan en la periferia del impulsor y generalmente se extienden hacia su sección interior. Una determinación teórica de la capacidad donde la pérdida de sustentación ocurre, es difícil, pero se puede aproximar cuando la geometría del álabe es conocida.

En la recirculación en la succión el daño se genera en el lado de alta presión del impulsor cerca del borde de entrada del álabe a través del metal hasta el lado de baja presión del álabe.

En el caso de la cavitación por NPSH inadecuado, el daño empieza en la zona de baja presión del impulsor y viaja a través de las paredes del álabe al lado de alta presión del mismo.

Cuando se presenta la recirculación en la descarga es difícil imaginar como una presión localizada en un punto a la descarga de un impulsor que generara una alta carga, pueda ser reducida a la presión de vapor del fluido, solo cuando se introduce el fenómeno de la recirculación.

Un flujo saliente y otro entrante en el mismo pasaje del impulsor pueden generar las velocidades requeridas para producir la cavitación. El esfuerzo cortante entre la interfase de las velocidades de entrada y de salida del líquido, generan vórtices de alta velocidad, provocando cavitación en su ojo o centro, generando la reducción de la presión hasta llegar a la presión de vapor del fluido. El resultado es ruido, vibración y daños derivados de la cavitación en la superficie del metal del impulsor y sus alrededores.
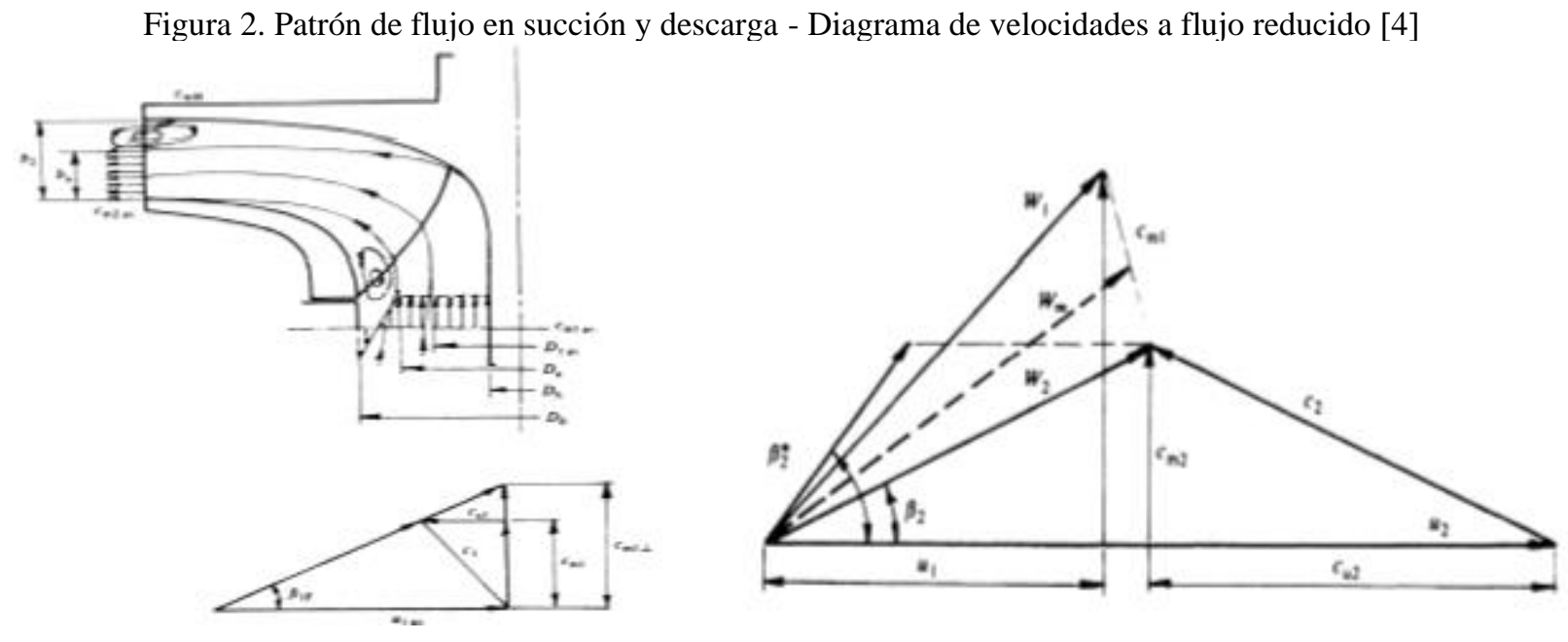

Los patrones de flujo que se presentan al interior de los pasajes de un impulsor se muestran en la figura No.1.3, en donde se aprecia la recirculación en la succión y la descarga, así como los efectos en la 
curvas de operación de la bomba, como son H-Q, NPSH-Q y P-Q. Es importante observar como las pulsaciones en la presión de descarga lleva al equipo a presentar vibración.

Figura 3.- Distintos tipos de Impulsores a diferentes velocidades específicas, el patrón de recirculación en la descarga y succión y su efecto en la curva característica [4]

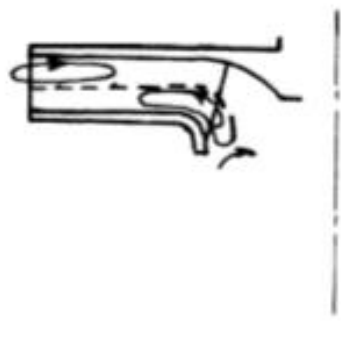

Low $n_{\mathrm{s}}$

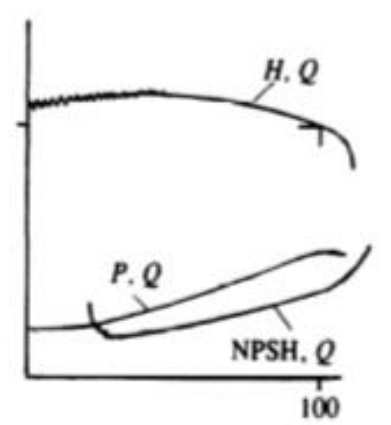

$\frac{Q}{Q_{\perp}}(\xi)$

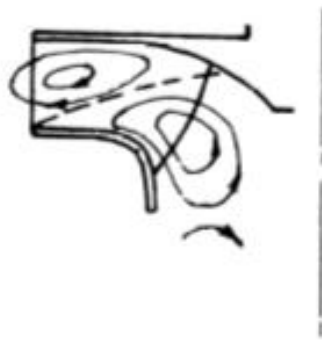

Medium $n_{\mathrm{s}}$

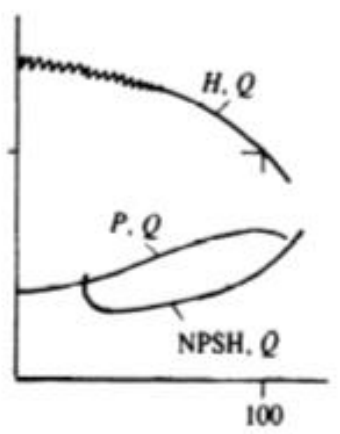

$\frac{Q}{Q_{\perp}}(\%)$

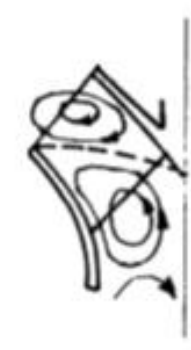

Mised flow

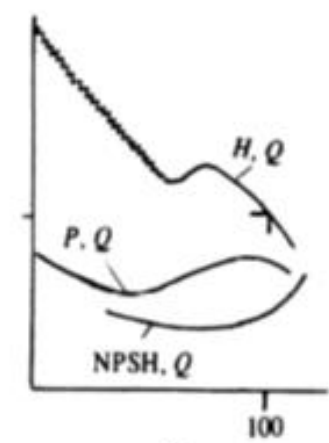

$\frac{Q}{Q_{+}}(\%)$
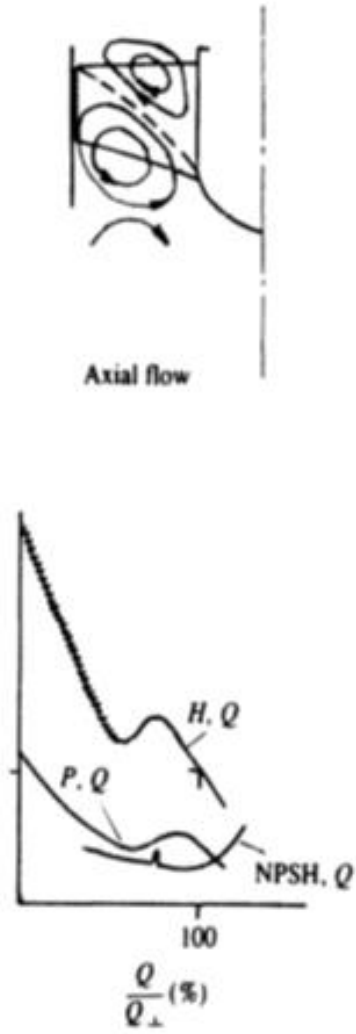

\section{METODOLOGÍA/DESARROLLO}

Existen varios métodos para el conocer los puntos donde se da la recirculación, sin embargo no se toman en cuenta distintos factores, como es el caso de la relación existente entre el diámetro de entrada y el diámetro exterior del impulsor, velocidad específica, velocidad específica de succión, etc.

Una forma indirecta para determinar la recirculación:

a. Incremento de temperatura

b. Incremento de la vibración

c. Fluctuación de la presión a carga parcial

d. Incremento de carga axial a bajo gasto

e. Incremento del empuje radial

De acuerdo con W.H. Fraser [1], el gasto donde se presenta la recirculación está dado por la relación: 


$$
\mathrm{Q}=\frac{D_{1} *\left(D_{1}{ }^{2}-h_{1}{ }^{2}\right) * R P M}{6.089 * 10^{9}} * \frac{v_{e}}{U_{1}} \quad \text { en } \mathrm{m}^{3} / \mathrm{s}
$$

$\mathrm{D}_{1}=$ Diámetro del ojo del impulsor

$\mathrm{h}_{1}=$ Diámetro de la Flecha en la parte central del impulsor o núcleo del impulsor

$\mathrm{U}_{1}=$ Velocidad tangencial o periférica en el ojo del impulsor

$\mathrm{V}_{\mathrm{e}}=$ Velocidad promedio en el ojo del impulsor

Hay información de fabricantes que recomiendan el gasto mínimo para evitar recirculación, en función de la velocidad específica, teniendo un determinado rango de transición, como se indica en la figura 4.

Figura 4.- Gráfica que indica el gasto mínimo para evitar recirculación, como un porcentaje del gasto de máxima eficiencia, en función de la velocidad especifica [3]

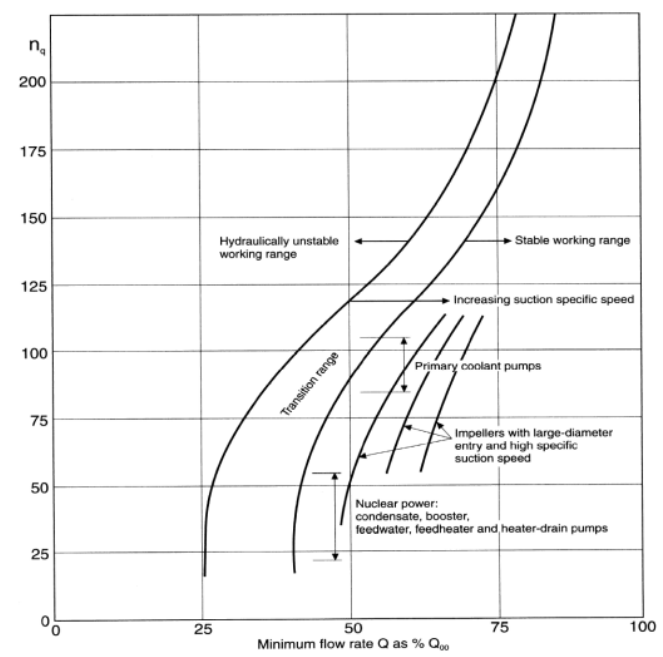

Figura 5.- Gráfica que relaciona la el gasto donde se presenta la recirculación en la succión con la velocidad del álabe en la succión y su ángulo de entrada $\beta_{1}[2]$
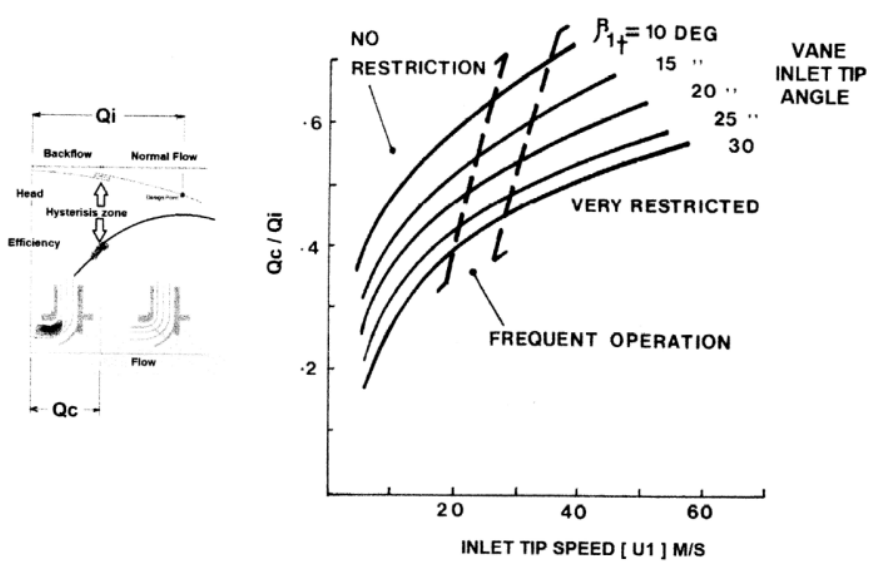


\section{RESULTADOS Y DISCUSIÓN}

Para poder demostrar la confiabilidad de los métodos presentados para cada una de las referencias enunciadas se determina donde se presenta el gasto de recirculación en la succión:

\subsection{BOMBA DE SUCCIÓN SIMPLE}

$\begin{array}{lll}\text { Velocidad } & 1750 \mathrm{rpm} & \\ \text { Gasto } & 0.11 \mathrm{~m}^{3} / \mathrm{s} & (1750 \mathrm{gpm}) \\ \text { Carga } & 45.72 \mathrm{~m} & (150 \text { pies }) \\ \mathrm{NPSH} & 5.18 \mathrm{~m} & (17 \text { pies }) \\ \mathrm{N}_{5} & 32.97 & (1708) \\ \mathrm{S}_{5} & 168.8 & (8744) \\ \mathrm{D}_{2} & 349.2 \mathrm{~mm} & (13.75 \text { pulgadas }) \\ \mathrm{B}_{2} & 31.75 \mathrm{~mm} & (1.25 \text { pulgadas }) \\ \mathrm{F}_{2} & 10645 \mathrm{~mm} 2 & (16.45 \text { pulgadas } \\ \mathrm{D}_{1} & 165.1 \mathrm{~mm} & (6.5 \text { pulgadas }) \\ \mathrm{h}_{1} & 0 & (0)\end{array}$

Para la metodología determinada por W.H. Fraser [1], se obtiene:

$$
\begin{gathered}
\mathrm{Q}=\frac{165.1 *(165.1) * 1750}{2.43 * 10^{10}} * 0.175 \quad \text { en } \mathrm{m}^{3} / \mathrm{s} \\
\mathrm{Q}=0.0567 \quad \mathrm{~m}^{3} / \mathrm{s}
\end{gathered}
$$

Es decir, 0.0567/0.11, o sea el $51.55 \%$ del gasto a máxima eficiencia.

Con la información obtenida en, Troubleshooting Centrifugal Pumps and their Systems [2], para determinar el gasto donde existe la recirculación de forma incipiente, se tiene lo siguiente:

Figura 6. Gráfica para determinar el gasto de recirculación

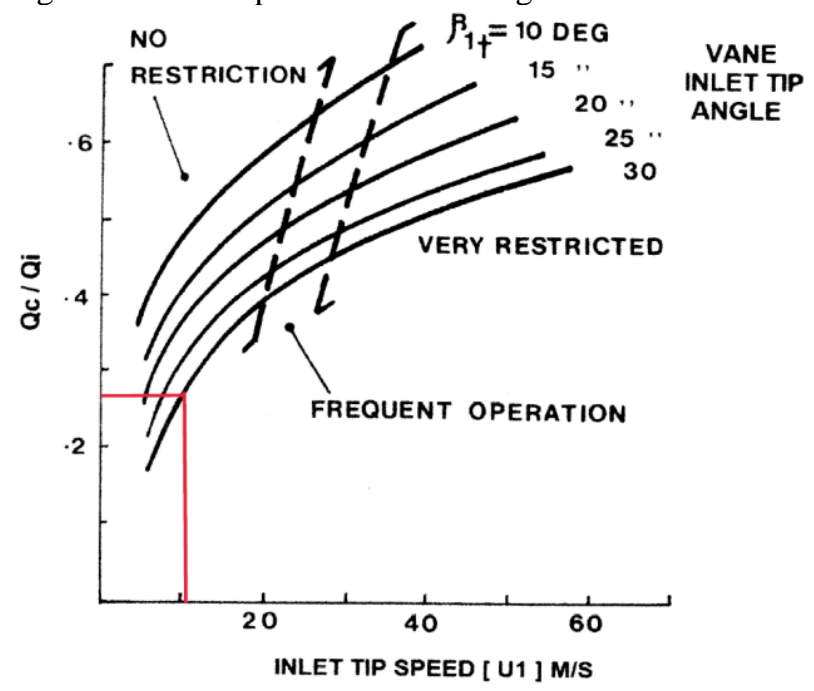

En donde $\mathrm{u}_{1}=15.13 \mathrm{~m} / \mathrm{s}$

$$
\beta_{1}=30^{\circ}
$$


La relación entre el gasto de la recirculación en la succión y el gasto a máxima eficiencia es 0.27 , es decir el gasto es:

$$
\mathrm{Q}=0.0297 \mathrm{~m} / \mathrm{s}
$$

Cada uno de los métodos representa una variación de uno con respecto al otro de casi el doble, lo cual indica la incertidumbre que existe en la valoración del fenómeno.

\section{CONCLUSIONES}

El fenómeno de la cavitación en el impulsor de una bomba es un proceso inestable y por lo tanto difícil de evaluar. Más aún si se considera que en su diseño, no solo se desarrollan los parámetros para la predicción de la eficiencia, sino que también, se determinan los valores límites en la operación del equipo, los cuales deben ser definidos por números adimensionales. La recirculación en las bombas centrifugas se presenta cuando un flujo en sentido inverso se genera en la succión o en la descarga del impulsor, en la zona de alta presión del álabe, derivado de trabajar el equipo a gasto reducido.

Es razonable indicar que la velocidad específica de succión, la velocidad específica, la relación del diámetro de la flecha o el cono de la succión en relación al ojo del impulsor, son variables fundamentales que definen la incidencia del fenómeno de la recirculación.

Al no tomarse en cuenta estas variables, el cálculo suele ser inexacto, y no puede determinarse para una solución confiable a un problema. Se requiere de métodos que suelan incluir todas las variables involucradas en el fenómeno. Así mismo de acuerdo con el costo del ciclo de vida de una bomba mostrado en la figura No. 7, del Hydraulic Institute, el mantenimiento y costo de energía son el 25 y $40 \%$ respectivamente, es decir un $65 \%$ del costo total de su vida útil, por lo que el fenómeno de la recirculación afecta de forma directa y en gran magnitud estos dos rubros, al verse disminuida la eficiencia y aumentar los problemas mecánicos del equipo.

Figura 7. Gráfica del Costo de Vida Útil de la Bomba

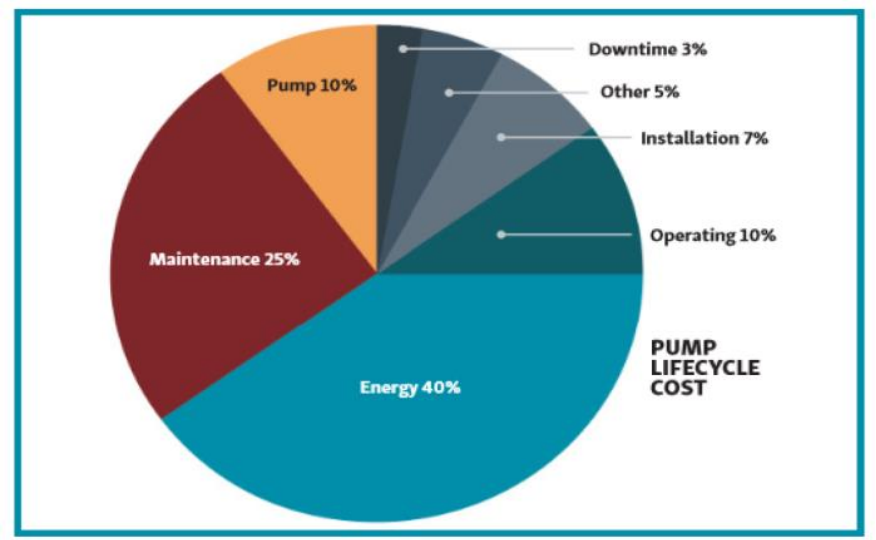




\section{REFERENCIAS}

[1] W.H. Fraser, Recirculation in Centrifugal Pumps, Mc. Graw-Edison Company,1981Edward Grist, Cavitation and the Centrifugal Pumps, A Guide for Pump Users, Taylor \& Francis, 1999.

[2] Ron Palgrave, Troubleshooting Centrifugal Pumps and their Systems, Elsevier/ButterworthHeinemann, 2020.

[3] Sulzer Pumps Ltd, Winterthur, Switzerland, Centrifugal Pumps Handbook, Third Edition, Elsevier, 2010.

[4] B. Neumann, The Interaction between Geometry and Performance of Centrifugal Pump, 1991. 